\title{
Evaluative Criteria of an English Language Textbook Evaluation Checklist
}

\author{
Jayakaran Mukundan (Corresponding author) \\ Department of Educational Studies, Faculty of Educational Studies, Universiti Putra Malaysia, 43400 UPM Serdang, \\ Selangor, Malaysia \\ Email: jayakaranmukundan@yahoo.com
}

Vahid Nimehchisalem

Department of Educational Studies, Faculty of Educational Studies, Universiti Putra Malaysia, Malaysia

Email: nimechie22@yahoo.com

\begin{abstract}
Checklists are instruments that help teachers or researchers in the area of English Language Teaching (ELT) to evaluate teaching-learning materials like textbooks. Several checklists are available in the literature, most of which lack validity. The paper discusses the results of a survey that investigated a group of English as a Second Language (ESL) experts' $(n=207)$ views on a checklist developed by the present researchers. The results showed an equal level of importance for all the items of the checklist. Additionally, based on the findings of factor analysis, two items were removed from the checklist. The study offers useful implications for ELT practitioners and researchers. Further research is necessary to field test the checklist for its validity and reliability.
\end{abstract}

Index Terms - English language teaching material evaluation, textbook evaluation checklists

\section{INTRODUCTION}

The textbook is one of the crucial factors in determining the learners' success in language courses. Teachers or curriculum developers, therefore, should select this teaching material carefully. Checklists are often used by experts in evaluating and selecting textbooks. Evaluation is made easier, more objective and valid when it is based on a reliable instrument. Most checklists available in the literature lack the expected validity or reliability (Mukundan \& Ahour, 2010). This necessitates the need for developing a checklist that is of high validity in terms of the construct domain of its evaluative criteria, that accounts for the consistency of the scores resulting from its items, and that is economical.

This study presents part of a project, the objective of which was to develop the English Language Teaching Textbook Evaluation Checklist (ELT-TEC). The project commenced by a review of the available instruments (Mukundan \& Ahour, 2010). In the light of the evaluative criteria in the available well-established checklists, the researchers developed a tentative checklist (Mukundan, Hajimohammadi, \& Nimehchisalem, 2011). This was followed by a qualitative study in which a focus group, including six ELT experts, helped the researchers enhance the clarity and inclusiveness of the checklist (Mukundan, Nimehchisalem, \& Hajimohammadi, 2011). Parallel with the focus group, a survey of a group of English as a Second Language (ESL) experts' views on the tentative checklist was conducted. The present paper reports the findings of this survey.

In developing checklists, two important matters stand out. One of them is determining the evaluative criteria that constitute the main skeleton o of any checklist and according to which textbooks are evaluated. The other crucial step is to decide on the level of importance or 'weight' of each criterion. This paper was mainly concerned with the second issue. With regard to their weightage, checklists may be of equal-weight or optimal-weight schemes. In an equal-weight scheme equal weights are assigned to each criterion whereas in an optimal-weight scheme different weights are assigned to each criterion. Most checklists available in the literature follow an equal weight scheme.

\section{OBJECTIVES AND RESEARCH QUESTIONS}

The objective of the study was to determine the degree of importance of each section alongside its related subcategories. The study also sought to test the practical significance of each item. The following research questions were addressed:

1. What is the degree of importance of each section and sub-category of the checklist?

2. Which items should be included in the final checklist?

\section{METHOD}

Quantitative method was used for collecting and analyzing the data. This section discusses the sample, instrument, and data analysis method used in the study. 


\section{A. Sample}

The sample included 207 English language teachers or lecturers (72.5\% female, aged between 20 and 67) in Malaysia.

\section{B. Instrument}

The instrument that was administered was a revised version of the tentative checklist for textbook evaluation (Mukundan, Hajimohammadi, \& Nimehchisalem, 2011). As presented in Appendix I, the checklist was converted into a 5-scale Likert style questionnaire which consisted of two parts. The first part elicited demographic information, like the respondents' gender, age, level of education, teaching context, as well as teaching experience. It also inquired whether the respondents had experienced any workshops related to textbook evaluation or selection and whether they had already been involved in textbooks evaluation or selection.

The second part presented the checklist to the respondents and asked them to read and rate the importance of each item from 0 (for unimportant) to 4 (very important). The respondents were told that they could add or delete sections, sub-categories, or items based on their own judgement. The second part of the questionnaire also provided two additional columns in front of each section, sub-category or item. In the first column, they could reword any part of this section or comment on it whenever they regarded it fit. The 'reword' and 'comment' columns would enable the researchers to collect some more qualitative data to support the findings or the focus group study (Mukundan et al., 2011).

\section{Data Analysis}

The collected data were analyzed using SPSS version 16. Descriptive statistics and Exploratory Factor Analysis were used for analyzing the data. Factor analysis can indicate how much variance is explained by each factor, or in the case of the present study, each sub-category (e.g., methodology, suitability to learners, physical and utilitarian attributes, etc.). Moreover, it can help instrument developers in grouping several items under a limited number of categories (Hair, Black, Babin, Anderson, \& Tatham, 2006). Such an application can prove very useful in developing instruments since it can help developers come up with a more economical instrument by collapsing certain components.

\section{RESULTS AND DiSCUSSION}

Table 1 shows the descriptive statistics related to the demographics of the respondents $(\mathrm{n}=207)$, who were $72.5 \%$ females, aged between 20 and 67.

TABLE I.

DESCRIPTIVE STATISTICS RESULTS OF THE DEMOGRAPHIC QUESTIONNAIRE

\begin{tabular}{|l|l|l|l|}
\hline Demographic feature & Category & Frequency & Percentage (\%) \\
\hline \multirow{4}{*}{ Gender } & Male & 57 & 27.5 \\
\cline { 2 - 4 } & Female & 150 & 72.5 \\
\hline \multirow{4}{*}{ Age } & 20-35 years of age & 112 & 54.1 \\
\cline { 2 - 4 } & $36-50$ years of age & 83 & 40.1 \\
\cline { 2 - 4 } & $51-67$ years of age & 12 & 5.8 \\
\hline \multirow{5}{*}{ Teaching context } & Diploma & 20 & 9.7 \\
\cline { 2 - 4 } & BA & 107 & 51.7 \\
\cline { 2 - 4 } & MA & 75 & 36.2 \\
\cline { 2 - 4 } & PhD & 5 & 2.4 \\
\hline \multirow{3}{*}{ Teaching experience } & School & 83 & 40.1 \\
\cline { 2 - 4 } & Language institute & 25 & 12.1 \\
\cline { 2 - 4 } & University & 99 & 37.8 \\
\cline { 2 - 4 } & $1-5$ years (low) & 82 & 39.6 \\
\cline { 2 - 4 } & $6-15$ (moderate) & 71 & 26.1 \\
\cline { 2 - 4 } & $16-35$ (high) & 54 & \\
\hline
\end{tabular}

As for their level of education, more than half of the respondents $(57.7 \%)$ held a bachelor degree $(57.7 \%)$. The remaining part had a diploma $(9.7 \%)$, master degree $(36.2 \%)$, or $\mathrm{PhD}(2.4 \%)$. Most of the respondents taught at university (47.8\%). Another large proportion (40.1\%) of the respondents comprised school teachers. Language institute instructors constituted the smallest group (12.1\%). The teaching experience of the respondents ranged between 1 and 35 years, with a majority $(39.6 \%)$ having a low and a minority $(26.1 \%)$ having a high teaching experience.

The questionnaire was administered to the respondents. The survey resulted in quantitative data that were analyzed using descriptive statistics and factor analysis methods, the results of which are discussed in this section. In order to answer the first research question; that is, the importance of each criterion, the mean and percentage of each criterion as rated by the respondents were calculated (Table 2). 
TABLE II.

DESCRIPTIVE STATISTICS RESULTS FOR THE IMPORTANCE OF CRITERIA

\begin{tabular}{|l|l|l|l|l|l|l|}
\hline No & Criteria & $\mathrm{n}$ & Sum & Mean & Std.* & $\%$ \\
\hline 1. & The book in relation to syllabus & 207 & 659 & 3.18 & .73 & 7.8 \\
\hline 2. & Methodology & 207 & 639 & 3.09 & .65 & 7.6 \\
\hline 3. & Suitability to learners & 207 & 640 & 3.09 & .68 & 7.6 \\
\hline 4. & Physical and utilitarian attributes & 207 & 626 & 3.02 & .64 & 7.4 \\
\hline 5. & Supplementary materials & 207 & 651 & 3.15 & .79 & 7.7 \\
\hline 6. & Listening & 207 & 642 & 3.10 & .75 & 7.6 \\
\hline 7. & Speaking & 207 & 661.5 & 3.19 & .72 & 7.8 \\
\hline 8. & Reading & 207 & 655 & 3.16 & .73 & 7.8 \\
\hline 9. & Writing & 207 & 651.5 & 3.15 & .79 & 7.7 \\
\hline 10. & Vocabulary & 207 & 662 & 3.20 & .66 & 7.9 \\
\hline 11. & Grammar & 207 & 645 & 3.12 & .66 & 7.7 \\
\hline 12. & Pronunciation & 207 & 636 & 3.07 & .72 & 7.6 \\
\hline 13. & Exercises & 207 & 656 & 3.17 & .70 & 7.8 \\
\hline
\end{tabular}

*Std.: Standard deviation

The results are expressed as mean $\pm \mathrm{SD}(\mathrm{n}=207)$. As it can be observed from the table, 'vocabulary' was rated as the

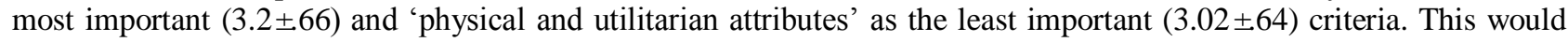
mean a range of $7.4 \%$ and $7.9 \%$; that is, an inconsiderable difference of $0.5 \%$ between the variables with the highest and lowest degree of importance. This finding suggests that the respondents regarded all the criteria as either 'important' (3.0) or 'very important' (4.0). Therefore, it is not necessary to assign weights for the criteria in the checklist. Such findings are in line with the literature in which most checklists are of an equal-scheme weight.

Factor analysis was used to analyze the data and provide an answer for the second question, the significance of each item. There are two points that should be considered before using factor analysis, the sample size and strength of intercorrelations among items. The appropriate sample size for factor analysis is a size of 10:1 (or a minimum of 5:1) ratio of respondents to items (Nunnally, 1978). The instrument had 38 items, so a size ranging between 190 and 380 would be appropriate for this study. The sample size of the present study, 207, falls within this range and is therefore suitable for factor analysis. Another criterion to check the adequacy of the sample size is Kaiser-Meyer-Olkin (KMO) Measure of Sampling Adequacy. If its value exceeds the threshold of .6, the sample size is adequate. Table 3 shows the SPSS output for KMO test.

TABLE III.

KMO AND BARTLETT'S TEST

\begin{tabular}{|l|l|l|}
\hline \multicolumn{2}{|l|}{ Kaiser-Meyer-Olkin Measure of Sampling Adequacy. } & .931 \\
Bartlett's Test of Sphericity & Approx. Chi-Square & $6.116 \mathrm{E} 3$ \\
\cline { 2 - 3 } & df & 703 \\
\cline { 2 - 3 } & Sig. & .000 \\
\hline
\end{tabular}

According to the table, the calculated value of KMO measure is .931 that is more than .6, which suggests the adequacy of the sample size. As for the strength of inter-correlations among items, based on the result of Bartlett's test of sphericity (Table 3), the significant value is smaller than alpha at .05 level of significance $(p=.000<\alpha=.05)$, which suggests that the data set is suitable for factor analysis.

The Varimax rotation technique was used to determine the factor loading of each item. Appendix II shows the results of this analysis. The rotated component matrix (Appendix II) can be used for two purposes. First, it helps researchers group different items under certain categories. Second, it can indicate which items are practically significant. With regard to grouping the items, since the results of factor analysis were not consistent with the literature, they were not followed in this study. The results were used for determining the level of significance of each item.

In Appendix II, the values in front of each component, or item, are called factor loadings that show the correlation between the original variables and the factors (Coakes \& Steed, 2007). Once the factor loadings are squared, they can indicate the percentage of variance in an original variable explained by a factor. Appendix III shows the squared factor loading of each item. The results were interpreted based on Hair et al's (2006) rule of thumb:

Unacceptable factor: $>.30$

Minimally acceptable factor: .30-.40

Acceptable factor: $.40-.50$

Significant factor .50<

As Hair et al. (2006) also point out, researchers' final decision on the number of the factors to be included in the final instrument should rely on the literature. Factor analysis results should only be regarded as recommendations. Table 4 presents the items categorized following Hair et al's (2006) rule of thumb. 
TABLE IV.

ITEMS CATEGORIZED BASED ON HAIR ET AL'S (2006) RULE OF THUMB

\begin{tabular}{|l|l|l|l|}
\hline Unacceptable items (>.30) & Minimally acceptable items $(.30-.40)$ & Acceptable items $(.40-.50)$ & Significant items $(.50<)$ \\
\hline $6,11,12,15,27$ & $3,4,5,7,14,16,17,18,20,28,29$, & $1,10,19,21,22,23,24$, & $2,8,9,13,37$ \\
& $30,31,32,38$ & $25,26,33,34,35,36$ & \\
\hline
\end{tabular}

According to the table, 5 items were regarded as unacceptable because their squared factor loadings were less than .30. These items included 'the compatibility to the learner needs' (item 6), 'efficient audio materials' (item 11), 'interesting tasks' (item 12), 'cultural sensitivities' (item 15), and 'vocabulary load' (item 27). According to the literature, these items are all important and should not be removed from the final checklist; however, a closer look at the items in the checklist shows their redundancy. As for item 6, there are already two other items (4 and 5) that consider the compatibility of the checklist to the learners' age and needs. Including another item would therefore sound unnecessary. The same argument also seems true for item 12 since the same feature has been repeated in items 24 (Texts are interesting), 26 (Tasks are interesting), and 32 (Examples are interesting). Therefore, it seems logical to remove this item based on the results of factor analysis. It may be argued that removing these items may lower the reliability of the instrument and that keeping them in the final checklist will not reduce its validity. It should, however, be noted that removing the unnecessary items will result in the higher economy of the instrument and enhance its usefulness.

Items 11, 15 and 27 were not removed from the final checklist, however. The reason was that regarding the literature, the researchers considered 'efficient audio materials' (item 11), 'cultural sensitivities' (item 15), and 'vocabulary load' (item 27) as important items. Removing these items would affect the construct validity of the checklist.

\section{CONCLUSION}

The paper presented the findings of the quantitative phase of a project that aims at developing a checklist to evaluate English language teaching textbooks. The main objective of the present study was to provide proof for the construct validity of the checklist. The results showed that the respondents viewed all the items as equally important. Two of the items were found to be redundant and were removed from the final checklist to improve its economy.

This study indicates how quantitative method can be employed to provide support for the validity of instruments in their development process. As it was also observed, factor analysis can help developers in making their instrument more economical. Despite their usefulness, factor analysis results must be handled cautiously and should be interpreted in the light of the related literature.

ESL researchers and teachers and particularly ELT material developers and evaluators will find the results of this research useful. The study also provides a practical guide for curriculum developers and indicates what constitutes a good textbook based on the views of ELT practitioners.

The findings of the present study helped the researchers further refine their checklist, which at this stage can be applied for evaluating textbooks more confidently. Future study will focus on the empirical test of the reliability and validity of the checklist.

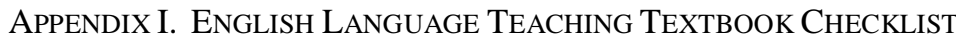

Dear respondent

This project aims at finding out what evaluative criteria are important for English language teachers or lecturers. Please answer the following questionnaire regarding your personal and professional background.

1. Gender: $\square$ Male $\square$ Female

2. Age: ...... years
3. Level of education:

4. Major:

$\square$ TESL

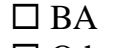

$\square$ Others

Teaching context:

6. Teaching experience:

$\square$ University ......years $\checkmark$ Female

7. Have you ever participated in any textbook evaluation workshops, seminars, courses, etc.?
$\square$ Yes $\quad \square$ No

8. If your answer to question 7 is 'Yes', please list the courses you attended.

a)

b)

c)

9. Have you ever evaluated a textbook?

$\square$ Yes

No

In the following section, you will find a list of the criteria that will be used to develop a checklist for evaluating English language teaching textbooks. You are requested to mark (0-4) to indicate the level of importance of each criterion according to this key:

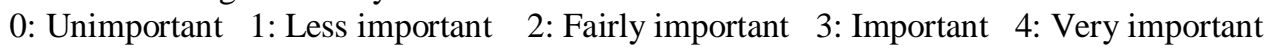


If you think a criterion is missing, you may add it to the end of the list and indicate its level of importance. In addition, if there is a term that, according to your experience, would be hard for evaluators to understand, you may add the term that you recommend in the column, Reword. If you have any further comments about each criterion, you may mention it in the Comment column.

Thank you for your cooperation.

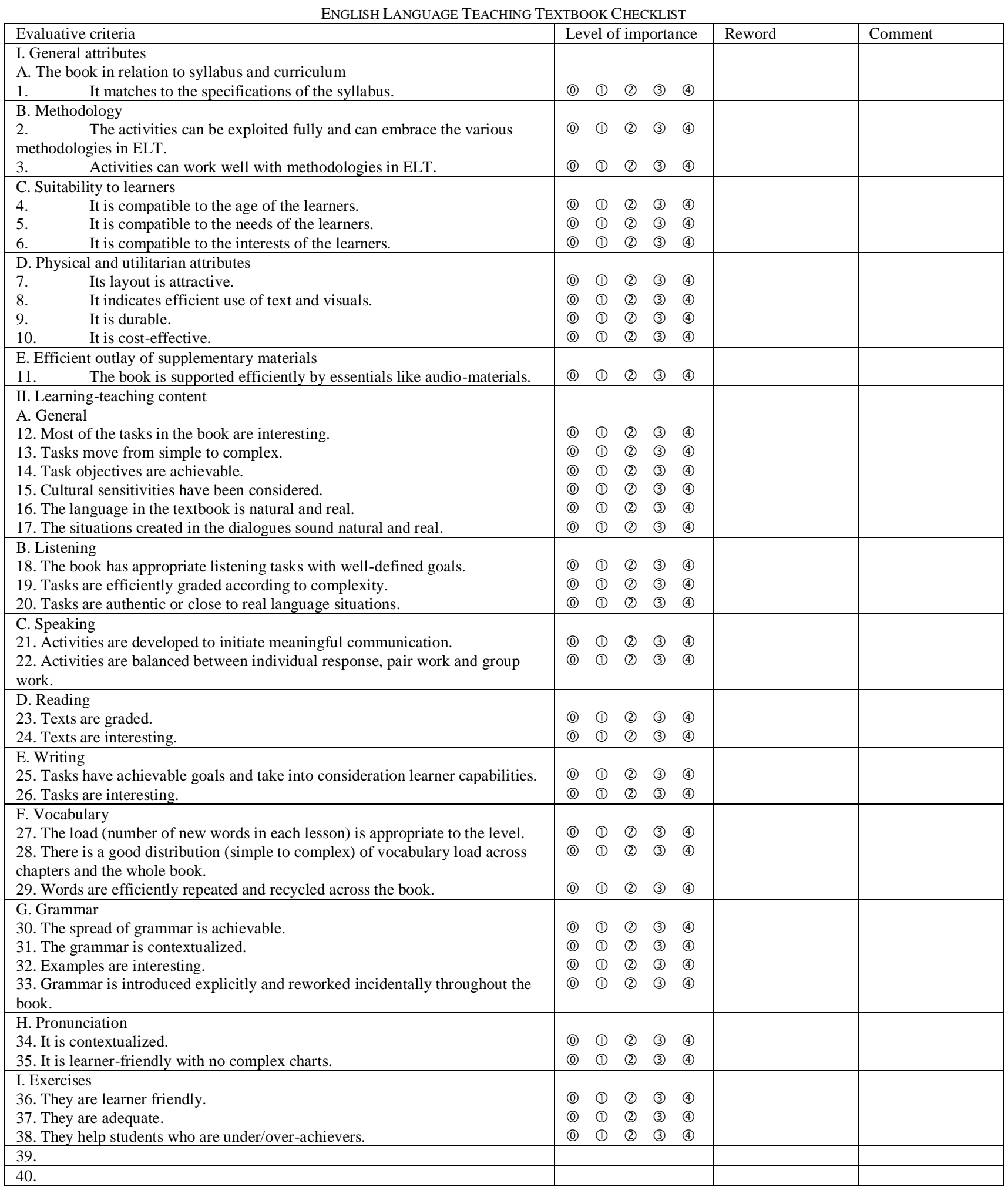




\begin{tabular}{|c|c|c|c|c|c|c|}
\hline & \multicolumn{6}{|c|}{ Component } \\
\hline & 1 & 2 & 3 & 4 & 5 & 6 \\
\hline II.D. Texts are interesting & .693 & & & & & \\
\hline II.C. Activities are developed to initiate meaningful communication & .675 & & & & & \\
\hline II.D. Texts are graded & .663 & & & & & \\
\hline II.E. Tasks have achievable goals and take into consideration learner capabilities & .661 & & & & & \\
\hline II.E. Tasks are interesting & .656 & & & & & \\
\hline II.C. Activities are balanced between individual response, pair work and group work & .635 & & & & & \\
\hline $\begin{array}{l}\text { II.F. There is a good distribution (simple to complex) of vocabulary load across } \\
\text { chapters and the whole book }\end{array}$ & .552 & & & & & \\
\hline II.F. The load (number of new words in each lesson) is appropriate to the level & .543 & & & & & \\
\hline II.I. They are adequate & & .715 & & & & \\
\hline II.H. It is learner-friendly with no complex charts & & .679 & & & & \\
\hline II.H. It is contextualized & & .656 & & & & \\
\hline II.I. They are learner friendly & & .654 & & & & \\
\hline $\begin{array}{l}\text { II.G. Grammar is introduced explicitly and reworked incidentally throughout the } \\
\text { book }\end{array}$ & & .654 & & & & \\
\hline II.G. The spread of grammar is achievable & & .579 & & & & \\
\hline II.G. The grammar is contextualized & & .570 & & & & \\
\hline II.I. They help students who are under/over-achievers & & .565 & & & & \\
\hline II.F. Words are efficiently repeated and recycled across the book & & .551 & & & & \\
\hline II.G. Examples are interesting & & .549 & & & & \\
\hline $\begin{array}{l}\text { I.B. The activities can be exploited fully and can embrace the various methodologies } \\
\text { in ELT }\end{array}$ & & & .734 & & & \\
\hline I.A. It matches to syllabus specifications & & & .688 & & & \\
\hline I.B. Activities can work well with methodologies in ELT & & & .626 & & & \\
\hline I.C. It is compatible to the needs of the learners & & & .596 & & & \\
\hline I.C. It is compatible to the age of the learners & & & .569 & & & \\
\hline I.C. It is compatible to the interests of the learners & & & .464 & & & \\
\hline II.B. Tasks are efficiently graded according to complexity & & & & .638 & & \\
\hline II.A. The situations created in the dialogues sound natural and real & & & & .629 & & \\
\hline II.B. The book has appropriate listening tasks with well-defined goals & & & & .621 & & \\
\hline II.A. The language in the textbook is natural and real & & & & .611 & & \\
\hline II.B. Tasks are authentic or close to real language situations & & & & .560 & & \\
\hline I.E. The book is supported efficiently by essentials like audio-materials & & & & .537 & & \\
\hline II.A. Cultural sensitivities have been considered & & & & .412 & & \\
\hline I.D. It is durable & & & & & .781 & \\
\hline I.D. It indicates efficient use of text and visuals & & & & & .724 & \\
\hline I.D. It is cost-effective & & & & & .660 & \\
\hline I.D. Its layout is attractive & & & & & .623 & \\
\hline II.A. Tasks move from simple to complex & & & & & & .726 \\
\hline II.A. Task objectives are achievable & & & & & & .625 \\
\hline II.A. Most of the tasks in the book are interesting & & & & & & .534 \\
\hline
\end{tabular}

Extraction Method: Principal Component Analysis. Rotation Method: Varimax with Kaiser Normalization. a. Rotation converged in 10 iterations.

APPENDIX III. SQUARED FACTOR LOADINGS 


\begin{tabular}{|c|c|c|}
\hline Item & Factor loading & Squared factor loading \\
\hline \multicolumn{3}{|l|}{ Section I } \\
\hline 1. It matches to the specifications of the syllabus. & 688 & .473 \\
\hline 2. The activities can be exploited fully and can embrace the various methodologies in ELT. & .734 & .539 \\
\hline 3. Activities can work well with methodologies in ELT. & .626 & .392 \\
\hline 4. It is compatible to the age of the learners. & .569 & .324 \\
\hline 5. It is compatible to the needs of the learners. & .596 & .355 \\
\hline 6. It is compatible to the interests of the learners. & .464 & .215 \\
\hline 7. Its layout is attractive. & 623 & .388 \\
\hline 8. It indicates efficient use of text and visuals. & .724 & .524 \\
\hline 9. It is durable. & .781 & .700 \\
\hline 10. It is cost-effective. & 660 & .436 \\
\hline 11. The book is supported efficiently by essentials like audio-materials. & .537 & .288 \\
\hline \multicolumn{3}{|l|}{ 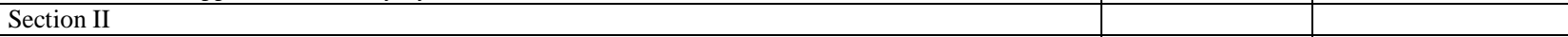 } \\
\hline 12. Most of the tasks in the book are interesting. & .534 & .285 \\
\hline 13. Tasks move from simple to complex. & .726 & .527 \\
\hline 14. Task objectives are achievable. & 625 & .391 \\
\hline 15. Cultural sensitivities have been considered. & .412 & .170 \\
\hline 16. The language in the textbook is natural and real. & 611 & .373 \\
\hline 17. The situations created in the dialogues sound natural and real. & .629 & .396 \\
\hline 18. The book has appropriate listening tasks with well-defined goals. & 621 & .386 \\
\hline 19. Tasks are efficiently graded according to complexity. & .638 & .407 \\
\hline 20. Tasks are authentic or close to real language situations. & .560 & .314 \\
\hline 21. Activities are developed to initiate meaningful communication. & 675 & .456 \\
\hline 22. Activities are balanced between individual response, pair work and group work. & 635 & .403 \\
\hline 23. Texts are graded. & 663 & .440 \\
\hline 24. Texts are interesting. & .693 & .480 \\
\hline 25. Tasks have achievable goals and take into consideration learner capabilities. & 661 & .437 \\
\hline 26. Tasks are interesting. & 656 & .430 \\
\hline 27. The load (number of new words in each lesson) is appropriate to the level. & .543 & .294 \\
\hline $\begin{array}{l}\text { 28. There is a good distribution (simple to complex) of vocabulary load across chapters and the } \\
\text { whole book. }\end{array}$ & .552 & .305 \\
\hline 29. Words are efficiently repeated and recycled across the book. & .551 & .304 \\
\hline 30. The spread of grammar is achievable. & .579 & .335 \\
\hline 31. The grammar is contextualized. & .570 & .325 \\
\hline 32. Examples are interesting. & .549 & .301 \\
\hline 33. Grammar is introduced explicitly and reworked incidentally throughout the book. & .654 & .428 \\
\hline 34. It is contextualized. & 656 & .430 \\
\hline 35. It is learner-friendly with no complex charts. & .679 & .461 \\
\hline 36. They are learner friendly. & .654 & .428 \\
\hline 37. They are adequate. & .715 & .511 \\
\hline 38. They help students who are under/over-achievers. & .565 & .319 \\
\hline
\end{tabular}

\section{REFERENCES}

[1] Coakes, S. J. \& L. Steed (2007). SPSS version 14.0 for Windows: Analysis without anguish. Melbourne: Wiley.

[2] Hair, J. F., W. C. Black, B. J. Babin, R. E. Anderson, \& R. L. Tatham. (2006). Multivariate data analysis (6th edn.). NJ: Pearson.

[3] Mukundan, J. \& T. Ahour. (2010). A review of textbook evaluation checklists across four decades (1970-2008). In B. Tomlinson, \& H. Masuhara. (eds.), Research for materials development in language learning: Evidence for best practice. London: Continuum, 336-352.

[4] Mukundan, J., R. Hajimohammadi, \& V. Nimehchisalem. (2011). Developing an English language textbook evaluation checklist. Contemporary Issues in Education Research. 4.6, 21-27.

[5] Mukundan, J., V. Nimehchisalem, \& R. Hajimohammadi. (2011). Developing an English language textbook evaluation checklist: A focus group study. International Journal of Humanities and Social Science, 1.12, 100-105.

[6] Nunnally, J. C. (1978). Psychometric theory (2nd edn.). New York: McGraw-Hill.

Jayakaran Mukundan is a Professor at the Faculty of Educational Studies, UPM, Malaysia and a Visiting Fellow at Leeds Metropolitan University, UK. He is also a Director on the Extensive Reading Foundation Board. His areas of interest include ESL writing and ELT textbook evaluation.

Vahid Nimehchisalem has been an English teacher, material developer, test developer, teacher trainer and lecturer. His main areas of research interest include assessing writing and ELT material evaluation. He completed his PhD in Teaching English as a Second Language (TESL) and, as a postdoctoral fellow, is now involved in research projects on ELT at the Faculty of Educational Studies, UPM, Malaysia. 